Pharmacokinetics and Drug Metabolism

\title{
Drug oxygenation activities mediated by liver microsomal flavin-containing monooxygenases 1 and 3 in humans, monkeys, rats, and minipigs
}

Miho Yamazaki $^{\text {a }}$, Makiko Shimizu ${ }^{\text {a }}$, Yasuhiro Uno ${ }^{\text {, }}$, and Hiroshi Yamazaki a,*

${ }^{a}$ Laboratory of Drug Metabolism and Pharmacokinetics, Showa Pharmaceutical University, Machida, Tokyo 194-8543, Japan and ${ }^{\mathrm{b}}$ Pharmacokinetics and Bioanalysis Center, Shin Nippon Biomedical Laboratories, Kainan 642-0017, Japan

${ }^{*}$ Correspondence author: Prof. Hiroshi Yamazaki

Showa Pharmaceutical University, 3-3165 Higashi-tamagawa Gakuen, Machida, Tokyo 1948543, Japan. Tel/fax: +81-42-721-1406; E-mail: hyamazak@ac.shoyaku.ac.jp 


\section{Abstract}

Liver microsomal flavin-containing monooxygenases (FMO, EC 1.14.13.8) 1 and 3 were functionally characterized in terms of expression levels and molecular catalytic capacities in human, cynomolgus monkey, rat, and minipig livers. Liver microsomal FMO3 in humans and monkeys and FMO1 and FMO3 in rats and minipigs could be determined immunochemically with commercially available anti-human FMO3 peptide antibodies or rat FMO1 peptide antibodies. With respect to FMO-dependent $N$-oxygenation of benzydamine and tozasertib and S-oxygenation of methimazole and sulindac sulfide activities, rat and minipig liver microsomes had high maximum velocity values $\left(V_{\max }\right)$ and high catalytic efficiency $\left(V_{\max } / K_{\mathrm{m}}\right.$, Michaelis constant) compared with those for human or monkey liver microsomes. Apparent $K_{\mathrm{m}}$ values for recombinantly expressed rat FMO3-mediated $N$ - and $S$ oxygenations were approximately 10- to 100-fold those of rat FMO1, although these enzymes had similar $V_{\max }$ values. The mean catalytic efficiencies $\left(V_{\max } / K_{\mathrm{m}}, 1.4\right.$ and $0.4 \min ^{-1} \mu \mathrm{M}^{-1}$, respectively) of recombinant human and monkey FMO3 were higher than those of FMO1, whereas $V_{\max } / K_{\mathrm{m}}$ values for rat and minipig FMO3 were low compared with those of FMO1. Minipig liver microsomal FMO1 efficiently catalyzed $N$ - and $S$-oxygenation reactions; in addition, the minipig liver microsomal FMO1 concentration was higher than the levels in rats, humans, and monkeys. These results suggest that liver microsomal FMO1 could contribute to the relatively high FMO-mediated drug $N$ - and $S$-oxygenation activities in rat and minipig liver microsomes and that lower expression of FMO1 in human and monkey livers could be a determinant factor for species differences in liver drug $N$ - and $S$-oxygenation activities between experimental animals and humans.

Keywords: FMO1, FMO3, human, minipig, benzydamine. 


\section{Introduction}

NADPH-dependent flavin-containing monooxygenases (FMO, EC 1.14.13.8) catalyze the oxygenation of a wide variety of nucleophilic compounds containing nitrogen or sulfur atoms [1,2] such as diet-derived chemical trimethylamine [3], anti-cancer agent tozasertib [4], and dipeptidyl peptidase IV inhibitor teneligliptin [5]. Only human FMO1 to FMO5 are functionally active among eleven human FMO genes identified (FMO1 to FMO11P) [6]. Human FMO3 is considered the prominent functional form expressed in adult human livers and is located in the membranes of the endoplasmic reticulum $[7,8]$. Examinations of adult human liver mRNA have revealed high FMO3 expression but low FMO1 expression $[9,10]$. In contrast, rat livers have been shown to express moderate levels of FMO1 protein [11-13]. Recently, we found that after birth, FMO1 and FMO3 in cynomolgus monkey livers were expressed at similar levels to FMO1 and FMO3 in human livers [14]. Pig FMO1 is known to be highly active in drug monooxygenations [3]; however, molecular analysis of pig and minipig FMO has not yet been fully reported. Experimental animals such as monkey, rat, and minipig are important species widely used in drug development as human models; however, the detailed characterization and comparison across species of drug oxygenation activities of FMO1 and FMO3 in liver microsomes or recombinantly expressed FMO proteins remain to be elucidated. It is important to compare and clarify both the contents and activities of FMO1 and FMO3 in liver microsomes in animal models.

Herein we report the $N$ - and $S$-oxygenation activities of liver microsomal enzymes from humans, monkeys, rats, and minipigs with respect to four typical FMO substrates 
(benzydamine, tozasertib, methimazole, and sulindac sulfide shown in Fig. 1) and also the activities of recombinantly expressed FMO1 and FMO3 from the same four species. The specific contents of FMO1 and FMO3 in liver microsomes from humans, monkeys, rats, and minipigs were measured. Low levels of FMO1 expression in human livers could be one of the determinant factors explaining species differences in liver FMO-dependent drug monooxygenation activities.

\section{Materials and Methods}

\subsection{Chemicals and enzymes}

Benzydamine hydrochloride, benzydamine $N$-oxide, methimazole, sulindac sulfoxide, and sulindac sulfide were purchased from Sigma-Aldrich (St. Louis, MO, USA). Tozasertib was purchased from Cayman Chemical (Ann Arbor, MI, USA). Pooled human liver microsomes (H150) were obtained from Corning (Tewksbury, MA, USA). Pooled liver microsomes from three male cynomolgus macaques (2-years of age), five male Wistar rats (7weeks), and three male minipigs (8-months of age, Microminipig registered as a variety of pig in the Japanese Ministry of Agriculture, Forestry and Fisheries, Fuji Micra Inc, Shizuoka, Japan) were prepared as described previously $[14,15]$. The other chemicals and reagents used were obtained in the highest grade commercially available.

\subsection{Molecular cloning of cDNAs and measurement of expression levels for minipig FMO1} and $\mathrm{FMO3}$

Total RNA from three male minipig livers was extracted using an RNeasy Mini Kit 
(Qiagen, Valencia, CA, USA) according to the manufacturer's protocols and was used for reverse transcription (RT)-polymerase chain reaction (PCR) and $\mathrm{qPCR}$ analysis. This study was approved by the Institutional Animal Care and Use Committee of Showa Pharmaceutical University. RT-PCR was performed as previously described $[14,16]$ using a pool of total RNAs extracted from three minipig livers and the expression levels of FMO1 and FMO3 were quantified.

Briefly, the RT reaction was performed in a mixture containing $1 \mu \mathrm{g}$ of total RNA, oligo(dT), and SuperScript III RT reverse transcriptase (Invitrogen, Carlsbad, CA, USA) at $50^{\circ} \mathrm{C}$ for $1 \mathrm{~h}$ according to the manufacturer's instructions. RT products were used as the template for PCR reactions, which were performed using KOD-Plus-Neo DNA polymerase (Toyobo, Osaka, Japan) with a thermal cycler (Applied Biosystems, Foster City, CA, USA) according to the manufacturer's protocols. The thermal cycler conditions were an initial denaturation at $94^{\circ} \mathrm{C}$ for 2 min and 35 cycles of $98^{\circ} \mathrm{C}$ for $10 \mathrm{~s}, 65^{\circ} \mathrm{C}$ for $30 \mathrm{~s}$, and $68^{\circ} \mathrm{C}$ for 1 min, followed by a final extension at $68^{\circ} \mathrm{C}$ for $5 \mathrm{~min}$. The primers used are listed in Table 1 . The PCR products were cloned into a vector using the Zero Blunt TOPO PCR cloning kit (Invitrogen) according to the manufacturer's instructions. The insert of each clone was sequenced using ABI PRISM BigDye Terminator v3.0 Ready Reaction Cycle Sequencing Kit (Applied Biosystems) with an ABI PRISM 3730 DNA Analyzer (Applied Biosystems). Raw sequence data were analyzed with DNASIS Pro (Hitachi Software, Tokyo, Japan), the Genetyx system (Software Development, Tokyo, Japan), and Sequencher (Gene Codes Corporation, Ann Arbor, MI, USA). For amino acid sequences of human, monkey, minipig, and rat FMOs (FMO1 and FMO3), multiple alignments were performed using the Clustal $\mathrm{W}$ program. A homology search was conducted using BLAST (National Center for Biotechnology 
Information) to compare the similarities of FMO1 or FMO3 amino acid sequences between minipigs and humans. The amino acid sequences used were human FMO1 (NP_665683) and FMO3 (NP_000838), monkey FMO1 (AHH29283) and FMO3 (AHH29287), and rat FMO1 (NP_036924) and FMO3 (NP_445885). The amino acid sequences of minipig FMO1 and FMO3 were deduced from the cDNAs obtained in this study.

Expression levels of FMO1 and FMO3 in three minipig livers were quantified by realtime RT-PCR, as described previously [16]. Briefly, RT reactions were carried out as described above using random primers (Invitrogen), one twenty-fifth of which was used for the subsequent PCR. The amplification was performed in a $20-\mu 1$ reaction using SYBR Green PCR Master Mix (Applied Biosystems) with the ABI PRISM 7500 sequence detection system (Applied Biosystems), according to the manufacturer's protocols. The primers (Table 1) were used at final concentrations of $200 \mathrm{nM}$. To determine the relative expression levels, the raw data were normalized with the $18 \mathrm{~S}$ ribosomal RNA level, which was measured using the TaqMan Pre-Developed Assay Reagents for Gene Expression (Applied Biosystems), based on three independent amplifications.

\subsection{Recombinant human, monkey, rat, and minipig FMO1 and FMO3}

Human and rat FMO1 and FMO3 expression plasmids were prepared as described previously $[8,17]$. Histidine-tagged monkey FMO1 and FMO3 expression plasmids were prepared as described previously [14]. Histidine-tagged minipig FMO1 and FMO3 expression plasmids were prepared in this study. PCR was performed as described earlier using the primers listed in Table 1 with each minipig FMO cDNA as a template, and the PCR products were digested with restriction enzymes (EcoRI for FMO1 and XhoI for FMO3) and 
subcloned into a pET30a vector (Novagen, Madison, WI, USA), which provides a $6 \times$ histidinetag at the $N$-terminus. $\quad$ Each protein was expressed in E. coli [JM109 or BL21(DE3)] using the expression plasmids prepared according to the manufacturer's protocols. Human FMO3 cDNA was similarly introduced into the pET-15b expression vector (Novagen), which provides a $6 \times$ histidine-tag at the $N$-terminus. This histidine-tagged human FMO3 protein was used as a secondary standard for detection of recombinantly expressed minipig FMO3 in bacterial membranes, which were not well recognized by anti-human FMO1 or FMO3 antibodies. Membrane preparations expressing FMOs were carried out as described previously [18].

The amounts of the recombinant human FMO proteins $\left(0.15-0.46\right.$ nmol FMO mg ${ }^{-1}$ bacterial membranes) were determined by immunoquantitation using commercial anti-human FMO1 or FMO3 antibodies (Corning, 458241 or 458243 ) by comparison with a standard of human FMO1 or FMO3 in insect cell microsomes (Corning) according to the manufacturer's data sheet [18]. The amounts of the recombinant monkey and minipig FMO proteins $(0.07-$ $0.12 \mathrm{nmol}$ FMO $\mathrm{mg}^{-1}$ bacterial protein) were determined by immunoquantitation using commercial anti-histidine tag antibodies (BioDynamics Laboratory, Tokyo, Japan) by comparison with a standard of the histidine-tagged human FMO3. The amounts of recombinant rat FMO proteins $\left(0.08-0.30 \mathrm{nmol} \mathrm{FMO} \mathrm{mg}^{-1}\right.$ bacterial protein) were determined by immunoquantitation using commercial anti-rat FMO1 peptide (ab116251) or anti-human FMO3 peptide (ab126790) antibodies (Abcam, Cambridge, UK) by comparison with standards of human FMO1 and FMO3 in insect cell microsomes (Corning). The final amount of recombinant FMO proteins in bacterial membranes were normalized to the FAD contents [19].

Expression levels of human and monkey FMO proteins in liver microsomes were determined by immunoquantitation using anti-human FMO1 or FMO3 antibodies by 
comparison with a standard of human FMO1 or FMO3 and recombinant monkey FMO1 or FMO3. Expression levels of rat and minipig FMO proteins in liver microsomes were determined by immunoquantitation using anti-rat FMO1 peptide or anti-human FMO3 peptide by comparison with a standard of recombinant rat FMO1 or FMO3 and minipig FMO1 or FMO3, respectively.

\subsection{Analysis of FMO1- and FMO3-mediated drug oxygenation activities}

Rates of $N$-oxygenation of benzydamine [20] and tozasertib [4] and S-oxygenation of methimazole [21] and sulindac sulfide [22] were determined using liquid chromatography in fluorescence mode or in UV detection mode, as described previously [23]. A typical incubation mixture consisted of $100 \mathrm{mM}$ potassium phosphate buffer $(\mathrm{pH} 8.4$, an optimal $\mathrm{pH}$ condition for the human FMO3), an NADPH-generating system (0.25 mM NADP ${ }^{+}, 2.5 \mathrm{mM}$ glucose 6-phosphate, and 0.25 units $\mathrm{ml}^{-1}$ glucose 6-phosphate dehydrogenase), substrate, and E. coli membranes expressing FMO protein (1.0-50 pmol FMO equivalent) or human liver microsomes $(0.02-0.3 \mathrm{mg}$ protein) in a final volume of $0.20 \mathrm{ml}$, unless otherwise stated. For FMO functional activity, the reactions were initiated in the presence of the NADPH-generating system by substrate addition because of the known instability of FMO enzymes and were incubated at $37{ }^{\circ} \mathrm{C}$ for $10-30 \mathrm{~min}$. Incubations were terminated by adding $0.20 \mathrm{ml}$ ice-cold acetonitrile or methanol. The aqueous supernatant was centrifuged at 2,000 $\mathrm{g}$ for $10 \mathrm{~min}$ and subjected to liquid chromatography equipped with an octadecylsilane (C18) column $(4.6 \mathrm{~mm}$ $\times 150 \mathrm{~mm}, 5 \mu \mathrm{m}$, Capcell Pak, Shiseido, Tokyo, Japan) [23]. The stabilities of authentic $N$ and $S$-oxide metabolites and negligible autoxidation of these substrates were confirmed to be stable under the preset experimental conditions. The kinetic analysis of $\mathrm{N}$ - or $\mathrm{S}$-oxygenations was performed using a nonlinear regression analysis in Michaelis-Menten model 
(KaleidaGraph, Synergy Software, Reading, PA, USA).

\section{Results}

\subsection{Molecular characteristics of minipig FMO1 and FMO3}

Because FMO1 has been identified and characterized in the pig [24], both FMO1 and FMO3 cDNAs were isolated from minipig liver. Minipig FMO1 and FMO3 cDNAs had open reading frames of 532 amino acid residues, and the deduced amino acid sequences contained the sequences characteristic of FMO proteins, including the GXGXXG/A motif (characteristic of FAD- and NADPH-pyrophosphate-binding sites) and the conserved EGLEP/FATGY sequences (Fig. 2). The minipig FMO3 amino acid sequence had high sequence identity (approximately 83\%) with human FMO3; this level of similarity was comparable to that of minipig FMO1, which had 88\% sequence identity to human FMO1. Phylogenetic analysis revealed a one-to-one relationship of minipig FMO3 to human, monkey, and rat FMO3; this relationship was similar to that for FMO1 (Fig. 3). Sequences of minipig FMO1 and FMO3 cDNAs identified in this study have been deposited in GenBank under accession numbers KC734480 and KC734484, respectively.

In minipig livers, both FMO1 and FMO3 genes were expressed, but the expression level of FMO1 was much higher (approximately 16-fold) than that of FMO3. Before quantitation of recombinantly expressed FMO1 and FMO3 proteins in bacterial membranes in this study, the cross-reactivities of four commercially available anti-FMO antibodies were investigated against human, monkey, rat, and minipig FMO1 and FMO3 (Table 2). Typical 
immunoblottings indicating the levels of FMO1 and FMO3 proteins in liver microsomes are shown in Fig. 4. It was found that recombinant human, monkey, rat, and minipig FMO1and FMO3 enzymes could all be detected immunochemically with anti-rat FMO1 peptide antibodies. Recombinant human, monkey, rat, and minipig FMO3 were detectable by either anti-human FMO3 peptide antibodies or FMO3 antibodies under the present conditions. FMO1 protein contents in rat and minipig liver microsomes could thus be normalized to the FMO3 protein contents in their livers.

The levels of human and monkey FMO1 proteins in liver microsomes were below the detection limits $(<1$ pmol FMO per mg protein, Table 3$)$. The human and monkey liver microsomal FMO3 contents were 20 and $30 \mathrm{pmol} / \mathrm{mg}$ protein, respectively. In contrast, the liver microsomal contents of rat FMO1 and FMO3 were 10 and $120 \mathrm{pmol} / \mathrm{mg}$ protein, respectively, and those for minipig FMO1 and FMO3 were 70 and $20 \mathrm{pmol} / \mathrm{mg}$ protein, respectively (Table 3). It was thereby established that human, monkey, and rat liver microsomes had higher contents of FMO3 than FMO1, whereas minipig livers had higher expression of FMO1 than FMO3.

\subsection{Kinetic parameters for $N$ - and $S$-oxygenation by liver microsomes}

Kinetic parameters for rates of $N$-oxygenation of benzydamine and tozasertib and $S$ oxygenation of methimazole and sulindac sulfide mediated by liver microsomes from humans, monkeys, rats, and minipigs were determined and analyzed by nonlinear regression (Table 4). The apparent $K_{\mathrm{m}}$ and $V_{\max }$ values for human liver microsomes for the two $\mathrm{N}$ - and two $\mathrm{S}$ oxygenation reactions were similar among the reactions. Monkey liver microsomes had slightly higher $K_{\mathrm{m}}$ values than human liver microsomes for these reactions, but the catalytic 
efficiencies $\left(V_{\max } / K_{\mathrm{m}}\right)$ were comparable with those of human liver microsomes. In contrast, rat and minipig liver microsomes had high $V_{\max }$ values and high catalytic efficiency $\left(V_{\max } / K_{\mathrm{m}}\right)$ compared with those for human or monkey liver microsomes, and the $K_{\mathrm{m}}$ values for these $N$ and S-oxygenations were similar to those for human liver microsomes. These results indicated that highly FMO-dependent $N$ - and $S$-oxygenation reactions are more likely to occur in rats and minipigs than in humans and monkeys.

\subsection{Kinetic parameters for $N$ - and $S$-oxygenation by recombinantly expressed FMO1 and FMO3}

The kinetic parameters for four $N$ - and $S$-oxygenation reactions mediated by recombinantly expressed human, monkey, rat, and minipig FMO1 and FMO3 were determined (Table 5). The apparent $K_{\mathrm{m}}$ values of human FMO3 for $\mathrm{N}$-oxygenation were similar to those of human FMO1, but for $S$-oxygenation of methimazole and sulindac sulfide the $K_{\mathrm{m}}$ values of human FMO1 and FMO3 were different. Human FMO3 had high $V_{\max }$ values and high catalytic efficiency $\left(V_{\max } / K_{\mathrm{m}}\right)$ for these four monooxygenations compared with those for human FMO1. Similarly, in the monkey, $V_{\max }$ and $V_{\max } / K_{\mathrm{m}}$ values were higher for FMO3 than for FMO1, except for benzydamine $N$-oxygenation. In contrast, the apparent $K_{\mathrm{m}}$ values for rat FMO3-mediated $N$ - and $S$-oxygenation were approximately 10 - to 100 -fold those of rat FMO1 (except for tozasertib $N$-oxygenation, which was 3 -fold), with similar $V_{\max }$ values for the two

enzymes. Minipig FMO1 efficiently catalyzed the $N$ - and $S$-oxygenation reactions. Overall, the apparent catalytic efficiencies $\left(V_{\max } / K_{\mathrm{m}}\right)$ of human and monkey FMO3 were high compared with those of FMO1, whereas the catalytic efficiencies of rat and minipig FMO3 were low compared with those of FMO1. 
The reaction velocity divided by the substrate concentration $(V /[\mathrm{S}])$ for $N$ - and $S$ oxygenation mediated by recombinant human, monkey, rat, and minipig FMO1 and FMO3 plotted against the substrate concentrations were investigated. Apparent $V /[\mathrm{S}]$ values for the four $N$ - and $S$-oxygenation reactions mediated by human FMO3 were higher than those mediated by human FMO1 at all substrate concentrations tested. Apparent $V /[\mathrm{S}]$ values for monkey FMO3 were only slightly higher than those for monkey FMO1 at all substrate

concentrations. In contrast, at low substrate concentrations, the apparent $V /[\mathrm{S}]$ values for rat FMO3 and minipig FMO3 were lower than those for the corresponding FMO1, except for rat tozasertib oxygenation.

\section{Discussion}

In this study, species differences in drug oxygenation activities mediated by FMOs were investigated. Because full-length minipig FMO3 cDNA has not been described to date, in this study, minipig FMO3 and FMO1 cDNAs were isolated and characterized. Sequence analysis revealed that FMO3 contained the amino acid sequence structures characteristic of FMO proteins (Fig. 2), and phylogenetic analysis showed a one-to-one relationship of minipig FMO3 to human, monkey, and rat FMO3, similar to the relationship for minipig FMO1 (Fig. 3). We previously reported that highly FMO-dependent benzydamine $N$-oxygenation and methyl p-tolyl sulfide $S$-oxygenation activities in minipig liver microsomes were comparable with those for humans, monkeys, and dogs [15]. The present results revealed that FMO1 was abundantly expressed in minipig liver microsomes (Table 3 and Fig. 3), and this abundant 
minipig FMO1 had high rates of $N$-oxygenation of benzydamine and tozasertib and $S$ oxygenation of methimazole and sulindac sulfide (Table 5). These high FMO1 levels and high catalytic capacities in minipig livers could account for the efficient catalysis of FMOdependent drug monooxygenations in minipig livers (Table 4). Because the present minipig showed similar P450 [15] and UDP-glucuronosyltransferase [25] activities among other three strains of minipigs (Yucatan, Sinclair, and Gottingen) commercially available, this stain could be representable for one of minipigs in this study.

In rat livers, relatively low levels of rat FMO1 (Table 3) with high monooxygenase activities (Table 5) and abundant levels of rat FMO3 with lower activities made different relative contributions to $\mathrm{N}$-oxygenation of benzydamine and tozasertib and $S$-oxygenation of methimazole and sulindac sulfide (Table 4). The relative contribution to overall activity of rat FMO3 in rat liver microsomes were different from those of monkey or human FMO3 in liver microsomes. Recombinant rat FMO1 had relatively low $K_{\mathrm{m}}$ values for the substrates with the exception of tozasertib (Table 5). Recombinant rat FMO3 appeared to have relatively high $K_{\mathrm{m}}$ values for benzydamine. The reason for these differences were not known at present but unknown differences in FMO1/3 anchoring in the membranes and/or larger substrate access channel dependent on the peroxy-flavin might be implied.

Monkey FMOs generally had similar functional characteristics to human FMOs. Abundant FMO3 (Table 3 [14]) was suggested to be important in drug monooxygenation in cynomolgus macaque livers, just as it is in human livers, although the relationships between the kinetic parameters of monkey FMO1 and FMO3 were slightly different from the predominant metabolic capacity of human FMO3 (Table 5).

From the viewpoint of the expanding interest in drug interactions mediated by human 
FMO3, sulindac sulfide $S$-oxygenation by human liver microsomal FMO3 could be a candidate for a model probe reaction $[23,26]$. Because rats and minipigs had higher catalytic capacities for liver microsomal FMO-dependent reactions than humans, the possible contribution of rat or minipig FMO1 might yield results in drug interaction studies that are not applicable to humans. In conclusion, the present results suggest that liver microsomal FMO1 could contribute to drug $N$ - and $S$-oxygenation activities in liver microsomes from rats and minipigs. Because of the many similarities between monkeys and humans in terms of FMO expression levels and catalytic activities, monkey FMO3-mediated drug monooxygenation can be considered a good tool for understanding human drug monooxygenases. Low levels of FMO1 expression in human and monkey livers could be key factors explaining the differences between humans/monkeys and rats/minipigs with respect to liver FMO-dependent drug monooxygenase activities.

\section{Acknowledgements}

The authors appreciate the technical assistance provided by Dr. Norie Murayama. This work was supported in part by the Ministry of Education, Culture, Sports, Science and Technology of Japan and the Japan Science and Technology Agency.

\section{References}

[1] Cashman JR, Zhang J. Human flavin-containing monooxygenases. Annu Rev Pharmacol Toxicol 2006;46:65-100.

[2] Krueger SK, Williams DE. Mammalian flavin-containing monooxygenases: structure/function, genetic polymorphisms and role in drug metabolism. Pharmacol Ther 2005;106:357-87.

[3] Ziegler DM. An overview of the mechanism, substrate specificities, and structure of FMOs. Drug Metab Rev 2002;34:503-11. 
[4] Catucci G, Gilardi G, Jeuken L, Sadeghi SJ. In vitro drug metabolism by C-terminally truncated human flavin-containing monooxygenase 3. Biochem Pharmacol 2012;83:5518.

[5] Nakamaru Y, Hayashi Y, Ikegawa R, Kinoshita S, Madera BP, Gunput D, Kawaguchi A, Davies M, Mair S, Yamazaki H, Kume T, Suzuki M. Metabolism and disposition of the dipeptidyl peptidase IV inhibitor teneligliptin in humans. Xenobiotica 2014;44:242-53.

[6] Hernandez D, Janmohamed A, Chandan P, Phillips IR, Shephard EA. Organization and evolution of the flavin-containing monooxygenase genes of human and mouse: identification of novel gene and pseudogene clusters. Pharmacogenetics 2004;14:117-30.

[7] Koukouritaki SB, Hines RN. Flavin-containing monooxygenase genetic polymorphism: impact on chemical metabolism and drug development. Pharmacogenomics 2005;6:80722.

[8] Shimizu M, Denton T, Kozono M, Cashman JR, Leeder JS, Yamazaki H. Developmental variations in metabolic capacity of flavin-containing monooxygenase 3 in childhood. $\mathrm{Br}$ J Clin Pharmacol 2011;71:585-91.

[9] Dolphin CT, Cullingford TE, Shephard EA, Smith RL, Phillips IR. Differential developmental and tissue-specific regulation of expression of the genes encoding three members of the flavin-containing monooxygenase family of man, FMO1, FMO3 and FM04. Eur J Biochem 1996;235:683-9.

[10] Zhang J, Cashman JR. Quantitative analysis of FMO gene mRNA levels in human tissues. Drug Metab Dispos 2006;34:19-26.

[11] Novick RM, Mitzey AM, Brownfield MS, Elfarra AA. Differential localization of flavincontaining monooxygenase isoforms 1, 3, and 4 in rat liver and kidney and evidence for expression of FMO4 in mouse, rat, and human liver and kidney microsomes. J Pharmacol Exp Ther 2009;329:1148-55.

[12] Mushiroda T, Yokoi T, Itoh K, Nunoya K, Nakagawa T, Kubota M, Takahara E, Nagata O, Kato H, Kamataki T. The house musk shrew (Suncus murinus): a unique animal with extremely low level of expression of mRNAs for CYP3A and flavin-containing monooxygenase. Comp Biochem Physiol C Toxicol Pharmacol 2000;126:225-34.

[13] Lattard V, Lachuer J, Buronfosse T, Garnier F, Benoit E. Physiological factors affecting the expression of FMO1 and FMO3 in the rat liver and kidney. Biochem Pharmacol 2002;63:1453-64.

[14] Uno Y, Shimizu M, Yamazaki H. Molecular and functional characterization of flavincontaining monooxygenases in cynomolgus macaque. Biochem Pharmacol 2013;85:1837-47.

[15] Murayama N, Kaneko N, Horiuchi K, Ohyama K, Shimizu M, Ito K, Yamazaki H. Cytochrome P450-dependent drug oxidation activity of liver microsomes from Microminipigs, a possible new animal model for humans in non-clinical studies. Drug 
Metab Pharmacokinet 2009;24:404-8.

[16] Uno Y, Fujino H, Kito G, Kamataki T, Nagata R. CYP2C76, a novel cytochrome P450 in cynomolgus monkey, is a major $\mathrm{CYP} 2 \mathrm{C}$ in liver, metabolizing tolbutamide and testosterone. Mol Pharmacol 2006;70:477-86.

[17] Kubota M, Nakamoto Y, Nakayama K, Ujjin P, Satarug S, Mushiroda T, Yokoi T, Funayama M, Kamataki T. A mutation in the flavin-containing monooxygenase 3 gene and its effects on catalytic activity for $\mathrm{N}$-oxidation of trimethylamine in vitro. Drug Metab Pharmacokinet 2002;17:207-13.

[18] Yamazaki H, Fujita H, Gunji T, Zhang J, Kamataki T, Cashman JR, Shimizu M. Stop codon mutations in the flavin-containing monooxygenase 3 (FMO3) gene responsible for trimethylaminuria in a Japanese population. Mol Genet Metab 2007;90:58-63.

[19] Batey DW, Eckhert CD. Identification of FAD, FMN, and riboflavin in the retina by microextraction and high-performance liquid chromatography. Anal Biochem 1990;188:164-7.

[20] Yeung CK, Rettie AE. Benzydamine $N$-oxygenation as a measure of flavin-containing monooxygenase activity. Methods Mol Biol 2006;320:157-62.

[21] Grothusen A, Hardt J, Brautigam L, Lang D, Böker R. A convenient method to discriminate between cytochrome $\mathrm{P} 450$ enzymes and flavin-containing monooxygenases in human liver microsomes. Arch Toxicol 1996;71:64-71.

[22] Hamman MA, Haehner-Daniels BD, Wrighton SA, Rettie AE, Hall SD. Stereoselective sulfoxidation of sulindac sulfide by flavin-containing monooxygenases. Comparison of human liver and kidney microsomes and mammalian enzymes. Biochem Pharmacol $2000 ; 60: 7-17$.

[23] Shimizu M, Yano H, Nagashima S, Murayama N, Zhang J, Cashman JR, Yamazaki H. Effect of genetic variants of the human flavin-containing monooxygenase 3 (FMO3) on N- and S-oxygenation activities. Drug Metab Dispos 2007;35:328-30.

[24] Poulsen LL, Ziegler DM. Multisubstrate flavin-containing monooxygenases: applications of mechanism to specificity. Chem Biol Interact 1995;96:57-73.

[25]. Higashi E, Ando A, Iwano S, Murayama N, Yamazaki H, Miyamoto S. Hepatic microsomal UDP-glucuronosyltransferase (UGT) activities in the microminipig. Biopharm. Drug Dispos., in press (DOI:10.1002/bdd.1898)

[26] Yamazaki H, Shimizu M. Survey of variants of human flavin-containing monooxygenase 3 (FMO3) and their drug oxidation activities. Biochem Pharmacol 2013;85:1588-93. 
Table 1. Sequences of primers used for cloning and analysis of minipig FMO1 and FMO3.

\begin{tabular}{cll}
\hline \multicolumn{1}{c}{ Name } & \multicolumn{1}{c}{ Sequence } \\
\hline Cloning & & \\
FMO1 & pigFMO1(5rt1)S & 5'-AGAACATGGCCAAGCGAGTTG-3' \\
& pigFMO1(3rt1)AS & 5'-CCATTCAGTAATACTTAGAGGAAAATCTGGAA-3' \\
FMO3 & pigFMO3(5rt1)S & 5'-AACAAAAGGTGACAATGGTGAAGAGAGT-3' \\
& pigFMO3(3rt1)AS & 5'-GTGATGATTAGAACAACACAAGCAAAACAG-3' \\
qPCR & & \\
FMO1 & mpFMO1 (5btj1)S & 5'-TACCCGAAGACAGGATACAACTAAGA-3' \\
& mpFMO1 (3btj1)AS & 5'-CTGTTAAATACCACGGAGTTTTCC-3' \\
& & \\
FMO3 & mpFMO3 (5btj1)S & 5'-CACGAGTAATAAAGGGAACTTGCAC-3' \\
& mpFMO3 (3btj1)AS & 5'-ATTGCTTTTGCCAAACCATTTTAG-3' \\
Preparation of expression plasmids & \\
FMO1 & mpFMO1 (5exp1)S & 5'-ATGGCCAAGCGAGTTGC-3' \\
& mpFMO1 (3exp1a)AS & 5'-CGGAATT-CAGTAATACTTAGAGGAAAATCTGGAAAATG-3' \\
& &
\end{tabular}


Table 2. Cross-reactivities of four commercially available anti-FMO antibodies to recombinantly expressed human, monkey, rat, and minipig FMO1 and FMO3 proteins.

\begin{tabular}{|c|c|c|c|c|c|c|c|c|}
\hline \multirow{2}{*}{ Antibodies } & \multicolumn{2}{|c|}{ Human } & \multicolumn{2}{|c|}{ Monkey } & \multicolumn{2}{|c|}{ Rat } & \multicolumn{2}{|c|}{ Minipig } \\
\hline & FMO1 & FMO3 & FMO1 & FMO3 & FMO1 & FMO3 & FMO1 & FMO3 \\
\hline $\begin{array}{l}\text { Anti-human } \\
\text { FMO1 }\end{array}$ & ++ & - & + & - & - & - & - & - \\
\hline $\begin{array}{l}\text { Anti-human } \\
\text { FMO3 }\end{array}$ & - & ++ & - & + & - & + & - & + \\
\hline $\begin{array}{l}\text { Anti-rat FMO1 } \\
\text { peptide }\end{array}$ & + & + & + & + & ++ & + & + & + \\
\hline $\begin{array}{l}\text { Anti-human } \\
\text { FMO3 peptide }\end{array}$ & - & + & - & + & - & ++ & - & + \\
\hline
\end{tabular}

Immunochemical responses of FMO1 and FMO3 expressed in bacterial membranes (0.1-3.0 pmol equivalent FMO) with four anti-FMO antibodies are shown in three categories: strongly reactive $(++)$, reactive $(+)$, and not detected $(-)$. 
Table 3. FMO1 and FMO3 expression in liver microsomes from humans, monkeys, rats, and minipigs.

\begin{tabular}{ccc}
\hline & \multicolumn{2}{c}{ pmol FMO / mg protein } \\
\cline { 2 - 3 } Liver microsomes & FMO1 & FMO3 \\
\hline Human & $<1$ & 20 \\
Monkey & $<1$ & 30 \\
Rat & 10 & 120 \\
Minipig & 70 & 20 \\
\hline
\end{tabular}

Amount of FMO1 and FMO3 in liver microsomes (5-10 $\mu \mathrm{g}$ protein) from humans, monkeys, rats, and minipigs were immunochemically determined with anti-rat FMO1 peptide antibodies and anti-human FMO3 peptide antibodies, respectively. 


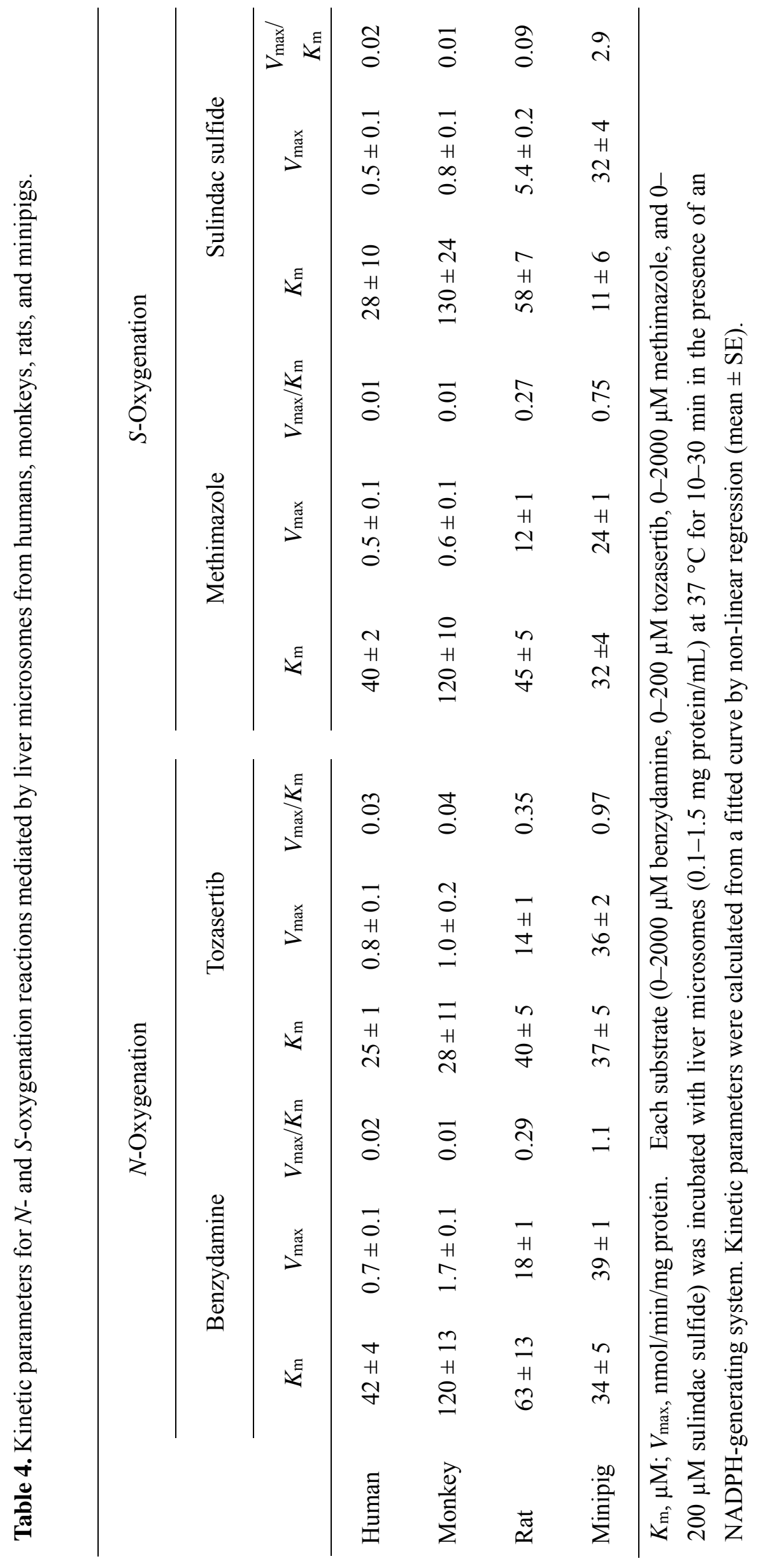




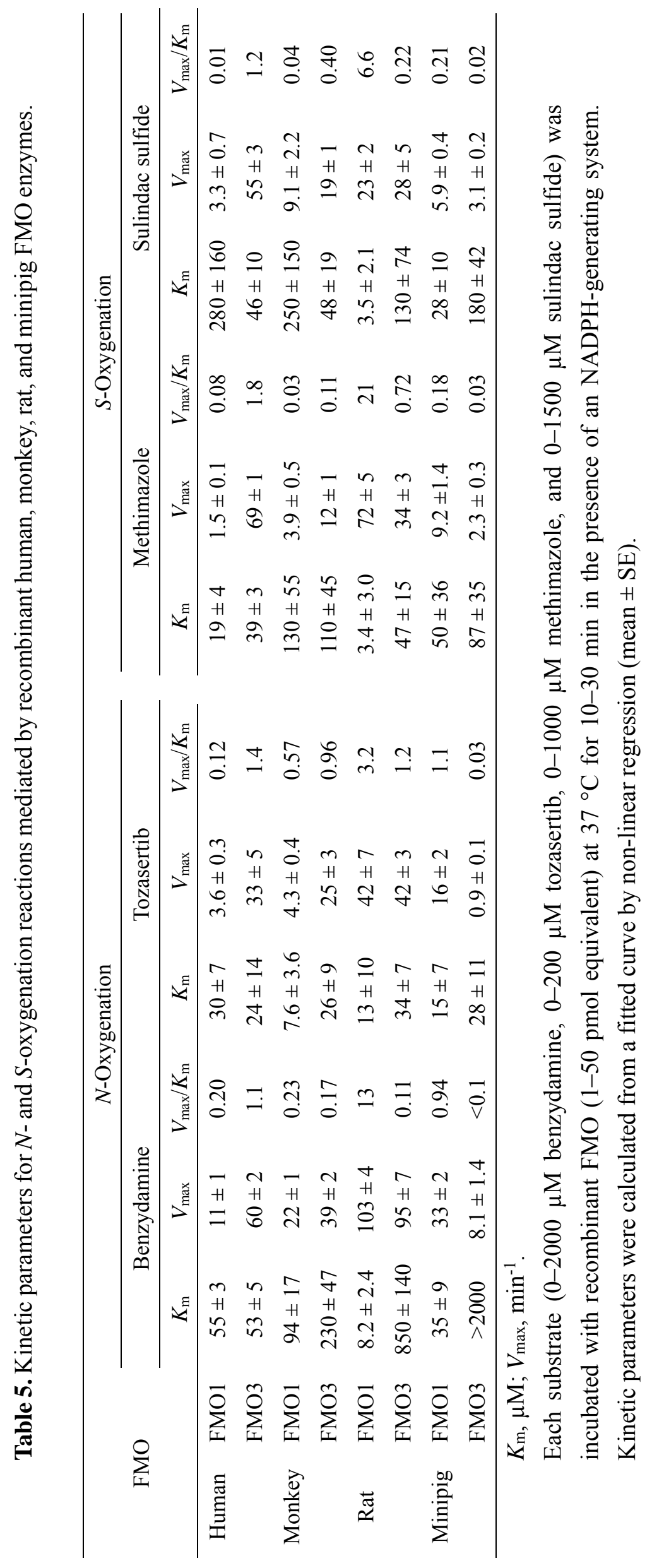




\section{Figure legends}

Fig. 1. Chemical structures of substrates used in this study.

Fig. 2. Multiple alignment of FMO1 and FMO3 amino acid sequences.

Minipig (mp) FMO1 and FMO3 amino acid sequences were aligned with human (h), monkey (m), and rat (r) FMO1 and FMO3 amino acid sequences. The sequences characteristic of FMO are shown by the solid lines above the sequences, including the GXGXXG/A motif (FAD- and NADPH-pyrophosphate-binding sites), and the conserved EGLEP and FATGY sequences. Asterisks and dots under the sequences indicate identical and conserved residues, respectively.

Fig. 3. Phylogenetic tree of FMO1 and FMO3 amino acid sequences.

The phylogenetic tree was created by the neighbor-joining method using FMO1 and FMO3 amino acid sequences from human (h), monkey (m), minipig (mp), and rat (r). The scale bar indicates 0.1 amino acid substitutions per site for distance measurement.

Fig. 4. Representative immunoblots of FMO1 and FMO3 in liver microsomes from humans, monkeys, rats, and minipigs.

Imunoblottings were performed using four commercially available antibodies: antihuman FMO1 antibodies (A), anti-human FMO3 antibodies (B), anti-rat FMO1 peptide antibodies (C, D), and anti-human FMO3 peptide antibodies (E), against liver microsomes and bacterial membranes expressing FMO1 or FMO3. (A) Lanes 1 and 2, pooled human liver microsomes (HLM, 5 and $10 \mu \mathrm{g}$ protein), lanes 3 and 4, human FMO1 (hFMO1, 1 and 2 pmol 
equivalent), lanes 5 and 6, pooled monkey liver microsomes (MLM, 5 and $10 \mu \mathrm{g}$ protein), lanes 7 and 8, monkey FMO1 (mFMO1, 0.14 and 0.24 pmol equivalent), lane 9, commercially available human FMO1 standard (std-1, 0.25 pmol). (B) Lane 1, commercially available human FMO3 standard (std-3, 0.125 pmol), lanes 2 and 3, pooled monkey liver microsomes (5 and $10 \mu$ g protein), lanes 4 and 5, monkey FMO3 (mFMO3, 0.2 and 0.4 pmol equivalent), lane 6, pooled human liver microsomes ( $5 \mu \mathrm{g}$ protein), lanes 7 and 8 , human FMO3 (hFMO3, 0.3 and 0.4 pmol equivalent), lane 9, human FMO3 standard (0.25 pmol). (C) Lane 1, human FMO1 standard (0.5 pmol), lanes 2 and 3, pooled rat liver microsomes (RLM, 5 and $10 \mu \mathrm{g}$ protein), lanes 4 and 5, rat FMO3 (rFMO3 1.5 and 3 pmol equivalent), lanes 6 and 7, rat FMO1 (rFMO1, 0.4 and 0.8 pmol equivalent). (D) Lanes 1 and 2, pooled minipig liver microsomes (PLM, 5 and $10 \mu \mathrm{g}$ protein), lanes 3 and 4, minipig FMO3 (pFMO3, 0.2 and 0.4 pmol equivalent), lanes 5 and 6, minipig FMO1 (pFMO1, 0.35 and 0.7 pmol equivalent), lane 7, human FMO1 standard (0.5 pmol). (E) Lanes 1 and 2, pooled minipig liver microsomes (5 and $10 \mu \mathrm{g}$ protein), lanes 3 and 4, minipig FMO3 (0.25 and 0.5 pmol equivalent), lanes 5 and 6, pooled rat liver microsomes (5 and $10 \mu \mathrm{g}$ protein), lanes 7 and 8, rat FMO3 (rFMO3, 0.75 and 1.5 pmol equivalent), and lane 9, human FMO3 standard (0.25 pmol). 
Fig. 1

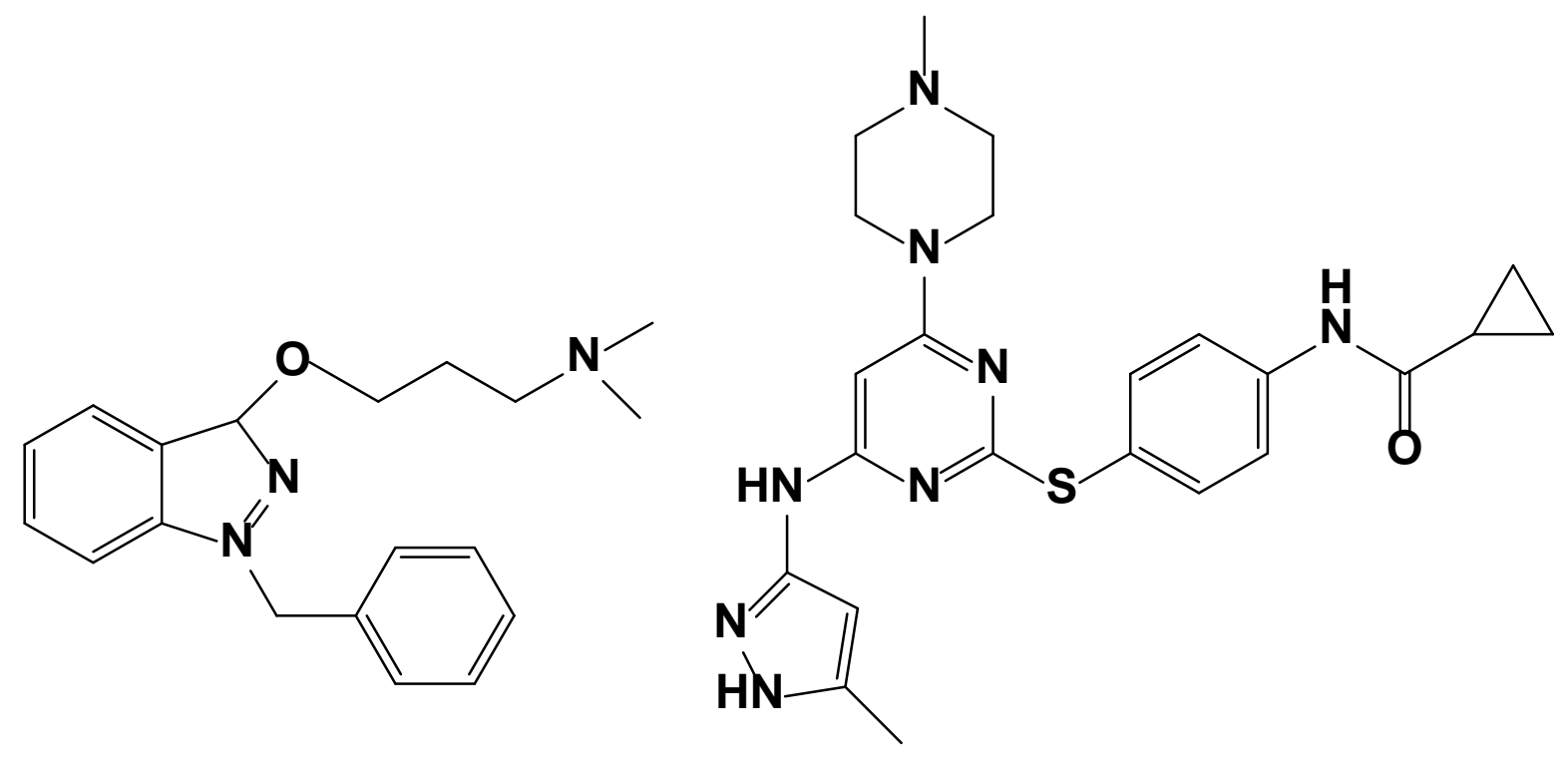

Benzydamine

Tozasertib
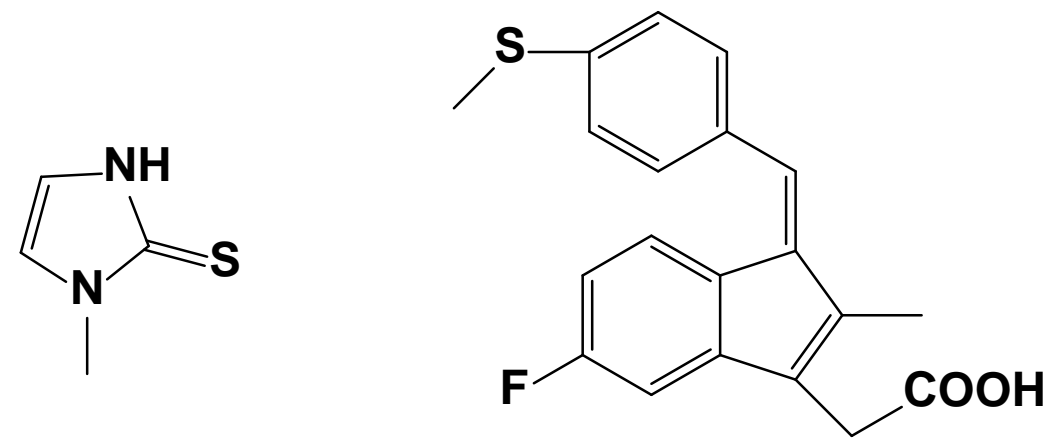

Methimazole

Sulindac sulfide 


\section{FAD EGLEP}

hFM01

mFM01

mpFM01

rFM01

hFM03

mFMO3

mpFM03

rFMO3

hFM01

mFM01

mpFM01

rFM01

hFMO3

mFM03

mpFM03

rFMO3

hFM01

mFM01

mpFM01

rFM01

hFMO3

$\mathrm{mFMO3}$

mpFMO3

rFMO3

hFM01

mFM01

mpFM01

rFM01

hFMO3

mFMO3

mpFM03

rFMO3

hFM01

mFM01

mpFM01

rFM01

hFM03

mFM03

mpFMO3

rFMO3

hFM01

mFM01

mpFM01

rFM01

hFMO3

mFMO3

mpFMO3

rFMO3

1: MAKRVAIVGAGVSGLASIKCCLEEGLEPTCFERSDDLGGLWRFTEHVEEGRASLYKSVVSNSCKEMSCYSDFPFPEDYPNYVPNSQFLEYLKMYANHFDL 10๑ 1: MAKRVAIVGAGVSGLASIKCCLEEGLEPTCFERSDDLGGLWRFTEHVEEGRASLYKSVVSNSCKEMSCYSDFPFPEDYPNYVPNSQFLEYLKMYANHFNL 10๑ 1:MAKRVAIVGAGVSGLASIKCCLEEGLEPTCFERSDDLGGLWRFTEHVEEGRASLYKSVVSNSCKEMSCYPDFPFPEDYPNYVPNSHFLEYLRMYANQFNL 10๑ 1: MVKRVAIVGAGVSGLASIKCCLEEGLEPTCFERSCDLGGLWRFTEHVEEGRASLYNSVVSNSSKEMSCYSDFPFPEDYPNFVPNSLFLEYLQLYATQFNL 10๑ 1:MGKKVAIIGAGVSGLASIRSCLEEGLEPTCFEKSNDIGGLWKFSDHAEEGRASIYKSVFSNSSKEMMCFPDFPFPDDFPNFMHNSKIQEYIIAFAKEKNL 10○ 1:MGKKVAIIGAGVSGLASIRSCLEEGLEPTCFEKSNDIGGLWKFSDHAEEGRASIYKSVFTNSSKEMMCFPDFPYPDDFPNFMHNSKIQEYLTAFAKEKSL 10○ 1: MVKRVAIIGAGISGLASIRSCLEEGLEPTCFERGEDVGGLWKFSDHAEEGRASIYRSVFTNSSKEMTCFPDFPFPDDFPNFMHNSKLQEYITAFAKEKNL 10๑ 1: MKRKVAVIGAGVSGLAAIRSCLEEGLEPTCFERSDDVGGLWKFSDHTEEGRASIYQSVFTNSSKEMMCFPDFPYPDDFPNFMHNSKLQEYITSFATEKNL 10๑

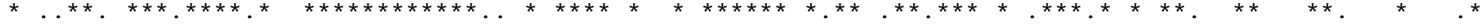

NADPH

101: LKHIOFKTKVCSVTKCSDSAVSGQWEVVTMHEEKQESAIFDAVMVCTGFLTNPYLPLDSFPGINAFKGQYFHSROYKHPDIFKDKRVLVIGMGNSGTDIA 200 101: LKHIQFKTKVCSVTKCSDFTVSGQWEVVTMHEEKQESAIFDAVMVCTGFLTNPYLPLDSFPGINAFKGQYFHSRQYKHPDIFKDKRVLVIGMGNSGTDIA 200 101: LKCIQFKTKVCSVTKHEDFNTTGQWDVVTLCEGKQESAVFDAVMVCTGFLTNPYLPLDSFPGINTFKGQYFHSRQYKHPDIFKDKSVLVVGMGNSGTDIA 200 101: LRCIYFNTKVCSITKRPDFAVSGQWEVVTVCQGKQSSDTFAAVMVCTGFLTNPHLPLDSFPGIQTFKGQYFHSRQYKHPDVFKDKRVLVVGMGNSGTDIA 200 101: LKYIQFKTFVSSVNKHPDFATTGQWDVTTERDGKKESAVFDAVMVCSGHHVYPNLPKESFPGLNHFKGKCFHSRDYKEPGVFNGKRVLVVGLGNSGCDIA 200 101: LKYIQFKTFVSSVNKRPDFATTGQWDVTTERDGKRESAVFDAVMVCSGHHVYPNLPKESFPGLNHFKGKCFHSRDYKEPGVFKGKRVLVVGLGNSGCDIA 200 101: LKYIQFKTLVSRVNKHPDFSITGQWDVTTEKDGQKESVVFDAVMICSGHHVYPNLPKESFPGLKLFKGKCFHSWDYKEPGLFKGKRVLVIGLGNSGCDIA 200 101: LKYIQFETLVTRINKCPDFSTTGKWEVTTEKNSKKETAVFDAVMICSGHHVYPHLPKDSFPGLNRFKGKCFHSRDYKEPGTWKGKRVLVIGLGNSGCDIA 200

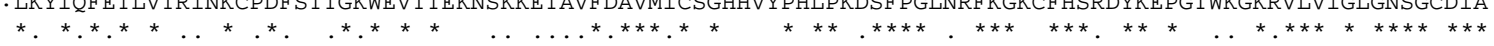

201: VEASHLAEKVFLSTTGGGWVISRIFDSGYPWDMVFMTRFQNMLRNSLPTPIVTWLMERKINNWLNHANYGLIPEDRTQLKEFVLNDELPGRIITGKVFIR 300 201: VEASHLAEKVFLSTTGGGWVISRIFDSGYPWDMVFMTRFQNMLRNSLPTPIVTWLMVRKINNWLNHANYGLIPEERTQLKEFVLNDELPGRIITGKVFIR 30๑ 201: VEASHLAKKVFLSTTGGAWVISRVFDSGYPWDMVFMTRFONMFRNSLPTPIVNWLIAKKMNSWFNHANYGLIPEDRIOLREPVLNDELPGRIITGKVLIK $30 \odot$ 201: VEASHLAKKVFLSTTGGAWVISRVFDSGYPWDMIFMTRFQNMLRNLLPTPVVSWLISKKMNSWFNHVNYGVAPEDRTQLREPVLNDELPGRIITGKVLIK $30 \odot$ 201 : TELSRTAEQVMISSRSGSWVMSRVWDNGYPWDMLLVTRFGTFLKNNLPTAISDWLYVKQMNARFKHENYGLMPLNGVLRKEPVFNDELPASILCGIVSVK 30๑ 201: TELSHTAEQVVISSRSGSWVMSRVWDNGYPWDMVLITRFGTFLKNNLPTAISDWLYMKQMNARFKHENYGLMPLNGVLRKEPVFNDELPACILCGIVSVK $30 \odot$ 201: TELSHTAEQVIISSRSGSWVMSRVWYDGYPWDVMTITRFETFLKNNLPTVISDWWYTKQMNARFKHENYGLIPLKRALRKEPVFNDELPACILRGTVSIK 300 201: AELSHVAQQVIISSRSGSWVMSRVWNDGYPWDMVVITRFQTFLKNNLPTAISDWWYMKQMNARFKHENYGLMPLNGTLRKEPVFNDELPARILCGTVSIK 300

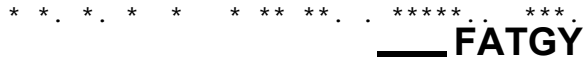

301 : PSIKEVKENSVIFNNTSKEEPIDIIVFATGYTFAFPFLDESVVKVEDGQASLYKYIFPAHLQKPTLAIIGLIKPLGSMIPTGETQARWAVRVLKGVNKLP 400 301: PSIKEVKENSVIFNNTSKEEPIDIIVFATGYTFAFPFLDESVVKVEDGQASLYKYIFPAHLQKPTLAIIGLIKPLGSMIPTGETQARWAVRVLKGVNKLP 400 301: PSIKEVKENSVVFNSSPEEEPIDIIVFATGYTFAFPFLDESVVKVEDGQASLYKYIFPAHLQKPTLAVIGLIKPLGSILPTGDTQARWAVRVLKGVNKLP 40๑ 301: PSIKEVKENSVVFNNTPKEEPIDVIVFATGYSFAFPFLDESIVKVEDGQASLYKYIFPAHLPKPTLAVIGLIKPLGSMIPTGETQARWVVQVLKGATTLP 40๑ 301: PNVKEFTETSAIFEDGTIFEGIDCVIFATGYSFAYPFLDESIIKSRNNEIILFKGVFPPLLEKSTIAVIGFVQSLGAAIPTVDLQSRWAAQVIKGTCTLP 40๑ 301: PNVKKFTETSAIFEDGTTFEGIDCVIFATGYSYAYTFLDESIIKNRNNEIILFKGVFPPLLEKSTIAVIGFVQSLGAAIPTVDLQSRWAARVIKGTCTLP 400 301: PNVREFTETSAIFEDGTVFEAIDCVIFATGYSYAYPFLDESIIKSRNNEVTLFKDIFPPVLEKPTMAVIGFVQSLGAAIPTADLQARWAARVIKGTCTLP 400 301: PNVKEFTETSAVFEDGTVFEGIDCVIFATGYGYAYPFLDDSIIKSRNNEVTLYKGIFPPQLEKPTMAVIGLVQSLGAAIPTTDLQARWAAQVIRGTCILP 400

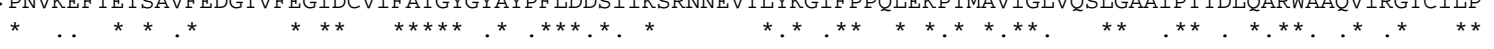

401: PPSVMIEEINARKENKPSWFGLCYCKALQSDYITYIDELLTYINAKPNLFSMLLTDPHLALTVFFGPCSPYQFRLTGPGKWEGARNAIMTQWDRTFKVIK 500 401: PPSVMIEEINARRENKPSWFGLCYCKALQSDYITYIDELLTYINAKPKLFSMLLTDPHLALTVFFGPCSPYQFRLTGPGKWEGARNAIMTQWDRTFKVTK 50๑ 401: PSSVMIQEVNTRKENKPSGFGLCYCKALQSDYIAYIDELLTYIDAKPNMFSLLLTDPHLALTIFFGPCTPYQFRLTGPGKWEGARNAIMTQWDRTFKVTK 50๑ 401: PPSVMMKEVNERKKNKHSGFGLCYCKALQSDYITYIDDLLTSINAKPDLRAMLLTDPRLALSIFFGPCTPYHFRLTGPGKWEGARKAILTQWDRTVNVTK 50๑ 401: SMEDMMNDINEKMEKKRKWFGKS - -ETIQTDYIVYMDELSSFIGAKPNIPWLFLTDPKLAMEVYFGPCSPYQFRLVGPGQWPGARNAILTQWDRSLKPMQ 498 401: SMEDMMNDINEKMERKRKWYGKS - -ETLQTDYIVYMDELSSFIGVKPNIPWLFLTDPKLAMEVYFGPCSSYQFRLVGPGKWPGARNAILTQWDRSLKPLQ 498 401 : SIKDIMHDIDEKMEKKLKWFGKS - NTIQTDYVVYMDELASFIGAKPNIPWLFLTDPKLALEVYFGPCSPYQFRLVGPGKWPGARNAILTQWDRILKPIT 498 401: SVNDMMDDIDEKMGKKLKWFGNS - -TTIQTDYIVYMDELASFIGAKPNILWLFLKDPRLAIEVFFGPCSPYQFRLVGPGKWSGARNAILTQWDRSLKPMK 498

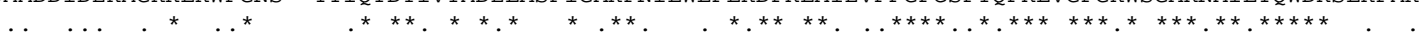

501: ARVVQESPSP - - FESFLKVFSFLALLVAIFLIFL 501 : GRVVQESPSP - -FESFLKLFSFLALLVAIFLIVL 501 : TRIVKESPSP - - FASLLKLFSFLALLVAIFQIFL 501: TRTVQETPST - - FETLLKLFSFLALLVAVFFIFL 499: TRVVGRLQKPCFFFHWLKLFAIPILLIAVFLVLT 499: TRVVGSLQKPRFFFHWLKLFAIPILLIAVFLGLT 499: TRVVGSPLKPCLFCSWFRPVVISAVSIAVLLVLF 499: TRDVGGIQKPCLYSHFLRLLAVPVL - IALFLVLI

$$
\text { . }{ }^{*} \quad . \quad \ldots . \quad \ldots{ }^{*} \ldots
$$


Fig. 3

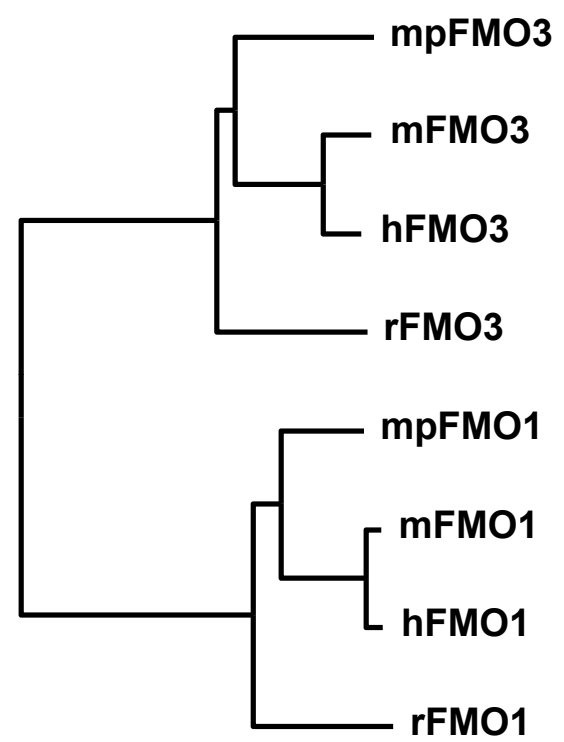

0.1 
Fig.4

A anti-human FMO1 antibodies

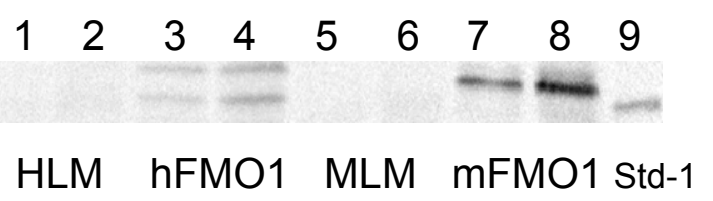

B anti-human $\mathrm{FMO} 3$ antibodies

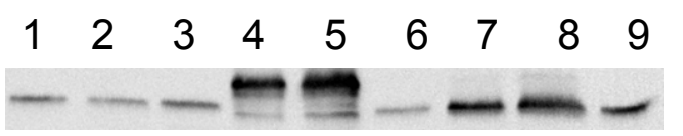

Std-3 MLM mFMO3 HLM hFMO3 Std-3

C anti-rat FMO1 peptide antibodies

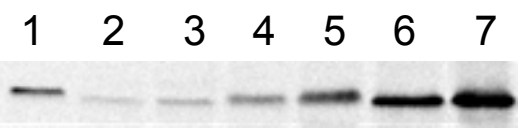

Std-1 RLM rFMO3 rFMO1

D anti-rat FMO1 peptide antibodies

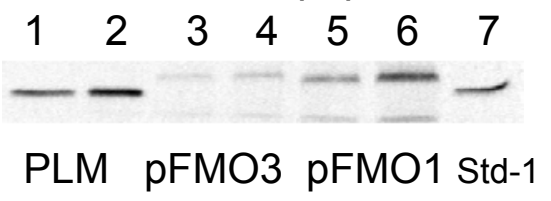

E anti-human $\mathrm{FMO} 3$ peptide antibodies

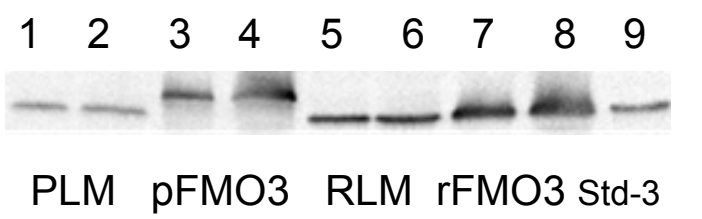

